\title{
Ulster University
}

\section{Building social capital in a divided city - the potential of events}

Devine, A., \& Quinn, B. (2019). Building social capital in a divided city - the potential of events. Journal of Sustainable Tourism, 27(10), 1495-1512. https://doi.org/10.1080/09669582.2019.1639721

Link to publication record in Ulster University Research Portal

\section{Published in:}

Journal of Sustainable Tourism

Publication Status:

Published online: 15/07/2019

DOI:

10.1080/09669582.2019.1639721

\section{Document Version}

Author Accepted version

\section{General rights}

Copyright for the publications made accessible via Ulster University's Research Portal is retained by the author(s) and / or other copyright owners and it is a condition of accessing these publications that users recognise and abide by the legal requirements associated with these rights.

\section{Take down policy}

The Research Portal is Ulster University's institutional repository that provides access to Ulster's research outputs. Every effort has been made to ensure that content in the Research Portal does not infringe any person's rights, or applicable UK laws. If you discover content in the Research Portal that you believe breaches copyright or violates any law, please contact pure-support@ulster.ac.uk. 
Title: Building social capital in a divided city - the potential of events

\begin{abstract}
It is widely held that social capital can help build sustainable communities (Cuthill 2010), yet researchers agree that further research is needed to fully understand the social dimensions of sustainable development (Getz 2009). In event settings, understanding how social capital is formed remains limited (Wilks 2011). This paper addresses this issue by examining the extent to which the UK City of Culture 2013 (CoC13) succeeded in building social capital in post-conflict Derry/Londonderry. The authors adopted a case study approach and mixed qualitative methods in the form of in-depth interviews and focus groups.
\end{abstract}

The findings suggest that $\mathrm{CoC} 13$ helped to generate both bonding and bridging social capital, however, while intra community bonds were strengthened, exclusivity was also fostered. More positive were the examples of bridging capital cultivated across communities, particularly between young attendees, and between event organisers, with cooperation building trust and goodwill between volunteers. Some of the cross community relationships developed have been sustained. However, the lack of legacy planning has meant that the long-term social goals have not been met. In summary, the study suggests that in a post conflict society, events can help build social capital. However, in the absence of legacy planning, the benefits gained may soon evaporate.

Keywords: Events; Political Conflict; Social Capital; Sustainable development; Legacy; Northern Ireland 


\section{Introduction}

Recently, policy makers and politicians across the world have shown increased interest in how the components of social capital: networks, shared values and trust; can be enhanced at local, regional and national levels (Muir, 2011). This interest is inspired by the belief that social capital can help build sustainable communities (Cuthill 2010, Kusakabe 2012), yet researchers are agreed that further research is needed to fully understand the social dimensions of sustainable development (Getz 2009). In the specific context of events, it is clear that policy makers see a potential to build social capital, with Smith (2012) discussing how the idea of building social capital and achieving greater community cohesion are now noted objectives of many event strategies. However, there remains a general lack of empirical research and a need for further investigation into how social capital can be strengthened through the hosting of events (Wilks 2011, Arcodia \& Whitford 2007). This paper aims to contribute to the discussion with an empirical case study of an event organised in a city characterised by deep societal divisions arising from decades of violence and political unrest. Specifically, it examines the UK City of Culture 2013 event (henceforth referred to as CoC13) hosted in Derry/Londonderry. One of the key objectives of $\mathrm{CoC} 13$ was to host a programme of events that would help bring communities in the city closer together. Using the theoretical lens of social capital, this paper examines how the $\mathrm{CoC} 13$ influenced community relationships in Derry/Londonderry in the immediate and longer term.

\section{Social Capital Theory}

Driven by fears over fragmentation of communities and a generalised decline in civic engagement (Foley, McGillivary \& McPherson, 2012), social capital has moved up the political agenda. Social capital is a complicated and contested concept. Bourdieu (1986) presents a sociological view of social capital, understanding it to both arise and be realised in all kinds of social networks (Adkins 2005), and viewing it primarily as a resource for individuals. Coleman (1988 p.98) meanwhile, views it as a resource that can be drawn upon collectively. He defines social capital by its functions and argues that its presence encourages certain actions which 
can facilitate the accomplishment of mutually beneficial ends. Like Coleman (1988), Putnam (1995 p.2) underlines the collective dimensions of social capital, defining it as "features of social organisation such as networks, norms and social trust that facilitate coordination and cooperation for mutual benefit". Interrelationships and connectivity between humans are central to the formation of social capital, hence why it is often described as the glue that holds society together (Murphy, 2008). A basic premise underpinning the work of all three theorists, and indeed social capital theory in general, is that investment in social relations is expected to yield a whole series of returns not only economically, but more widely in terms of building sustainable communities. Coleman (1988: p. 94), for example, suggests that the "sustainability of community relates to the ability of society itself, or its manifestation as local community, to sustain and reproduce itself at an acceptable level of functioning in terms of social organization". More recently, other researchers have argued that high levels of social capital can lead to increased local capacity to create more environmentally friendly and more socially equitable places to live (Bridger and Lulott 2001) and can help achieve sustainability goals (Kusakabe 2012). According to Ooi, Laing and Mair (2015) stocks of social capital are associated with building shared understandings and a sense of community. While more research is needed to fully understand the link between sustainable community development and social capital, 'there appears to be increasing support for it as a useful theoretical concept relating to building strong, resilient, healthy or socially sustainable communities' Cuthill (2011 p.367).

In the literature on social capital, a distinction is widely made between bonding (exclusive) and bridging (inclusive) forms. Putnam (1993) explains that bonding social capital is inward looking and characterised by strong ties that reinforce exclusive identities, promote homogeneity and create strong in-group loyalty; whereas bridging social capital is outward looking, involves weaker ties and promotes links between diverse individuals and groups. Putnam suggests that many groups simultaneously bond across some social dimensions and bridge across others. In general, the dominant sense is that social capital is a force for good. However, Leonard (2004) and others have problematized the fact that it is often considered to be a quick-fix solution to complex, long-term structural problems. 
Over time, it can be said that the growing social capital literature has developed a more critical lens acknowledging the inadequacies of the basic framework without abandoning the concept altogether (Muir 2011). For example, in their critique of Putnam's work, Portes and Landolt (1996) discuss how in some cases, social capital can constrain individuals' actions and choices. Writing about ethnically diverse societies transitioning away from conflict, Pickering (2006) discusses how social capital can threaten democracy. While strong ties foster high levels of trust and connect groups of people together through bonding capital, they can simultaneously serve to deepen the divisions, differences and lack of trust that separate groups from other cohorts. Leonard (2004) makes a very similar case in respect of politically contentious societies, arguing that trust within tightly bonded communities at a local level may engender distrust of wider institutions, reinforcing "them versus us" mentalities. Ooi et al. (2015) writing in the context of mountain resort tourism conclude that while high levels of bonding social capital help to build solidarity and loyalty among community members, a lack of bridging capital limits the inclusion of newcomers. Given that the acknowledged value of social capital lies in the access it can afford to networks, resources and information that help advance the life chances of the actors and community groups involved, the value of having open, diverse and inclusive relationships that link outwards to other resources is critical. Thus for Dale and Newman (2010) the value of what is referred to as bridging capital cannot be over-emphasised. They conceive of bridging capital as relationship building that leads to accessing external resources, and links with others who move in different circles (Wilks, 2011).

\section{Social Capital and Events}

As Liu (2017) points out, festival and event researchers have long emphasised the ways in which events are implicated in network and relationship building (Getz, Andersson \& Larson 2006), and in creating notions of belonging, connectivity and identity (Duffy and Mair 2018). It is therefore not surprising that social capital has gained currency in the festival and event literature, particularly as the need to expand investigations beyond the economic has become established. An early publication by Misener and Mason (2006: 44) supported Coleman's (1988, p.22) basic premise that "social capital lies in the collective sense of responsibility generated by broad-based participation in community initiatives". Writing in the context of 
sports events, they advocated using social capital to investigate how events contribute to building community networks, relationships of trust and reciprocity, and social inclusion. Arcodia and Whitford (2007), in another early discursive contribution to the literature suggested that by organising and attending festivals, communities build community resources, generate and reinvigorate links between groups and individuals, promote social cohesion, and create opportunities for public celebration. Successive researchers have focused on social capital generation in respect of specific cohorts of actors like residents (Finkel, 2010), audiences (Wilks, 2011), and organisers (Mykletun, 2009). Liu (2017) also focused on networking among organisers, linking cultural events with increases in networking, organisational learning, increased profile and confidence within the cultural sector more generally, outcomes that contribute to building sustainability. Wilks (2011) focused on attendees, introducing the concepts of bridging and bonding social capital into the event context to investigate the extent to which festival attendees create and deepen social relationships and social bonds. She found bonding capital to be an important part of the festival experience. The formation of bridging social capital: i.e. new and enduring social connections with previously unconnected attendees was not, however, found to be a feature of festivals, despite a sense of general friendliness and trust identified by some. Quinn and Wilks (2013) also used Putnam's (2000) twin concept of bridging and bonding social capital and found bonding social capital to be prevalent among family and friendship groups among festival attendees, while bridging social capital was generated across different sets of social actors, for example, between attendees and performers, performers and music industry personnel.

Wilks and Quinn (2016) pointed to the dynamic nature of social capital formation and the gradual transformation of weak bridging ties into stronger bonding ties as familiarity and closer social relations developed between local residents and repeat visitors, and among repeat visitors themselves, over time. In doing so they highlight the dynamic nature of social capital and implicitly reference Coleman's (1990) argument that social capital is potentially transient. Social capital also has a spatial dimension (Rutten, Westland and Boekema 2010), and there is a growing awareness that while 'city space imbues the festival with meaning, the process is reciprocal because the festival provides new meanings for the city it inhabits' (Johansson and Kociatkiewicz, 2011). Festivals and events effect spatial transformations, 
changing the routine appearance, ambiance and use of space (Johansson and Kociatkiewicz, 2011) and creating what Pløger, (2010 p.853), called 'an atmosphere of potentials'.

Thus, a growing number of researchers agree that festivals and events have the potential to unite diverse actors and stakeholders behind a common purpose, engage in public celebration and so build social capital. However, there are caveats. González Reverté and Miralbell-Izard (2011) stress that they may build social cohesion only among those who share a similar worldview. In this, they express a concern shared by other researchers working with social capital ideas in other community development contexts (e.g. Leonard 2004). Given that all events are both culturally constructed and produced within the context of prevailing power relations (Waterman 1988), the cohesion fostered can serve to perpetuate existing social and cultural divisions and to exclude as well as include. Social capital is premised on the connectivity of human activity (Misener, 2013) but if positive social capital is to be fostered, González-Reverté and Miralbell-Izard's (2011, p.72) reminder "that multiculturalism or cultural heterogeneity in society may complicate potential social capital growth, alienate groups, or require the negotiation of cultural diversity" is salient. Writing about an intercommunity sports event in ethnically divided Sri Lanka, Schulenkorf, Thomson and Schlenker (2011, p.117) concluded that positive experiences gained from intergroup socialising and celebrating "may contribute to the stock of social capital available to participating communities". Both these authors and de Jong and Varley (2018) point to the weight of historically and politically embedded factors that can serve to constrain efforts to build links across diverse groups of actors. They stress that careful, integrated planning and reform are needed if events are to serve as a means of promoting bridging capital. The latter draw attention to the role played by relevant institutions in this regard. According to social network theory, institutions can actively encourage the development of social capital by being culturally diverse, valuing cross-cultural cooperation, and encouraging repeated, mutually dependent interactions between different social cohorts (Pickering 2006). In addition, analysing social capital requires that the contextual particularities of host communities are considered (Ziakas, 2013). Mohan and Mohan (2002) argue that forms of social capital vary considerably depending on the geographical, political, economic and socio-cultural characteristics of the host community. Community itself is another term that requires careful attention with Laing and Mair (2015) describing it as a very complex term often used without 
scrutiny and Shirlow and Murtagh $(2006$, p.57) cautioning against treating it as a "distinctive stakeholder with a shared set of values".

All of the foregoing suggests that while research into events and social capital is increasing, many opportunities for further enquiry exist. Few studies have empirically considered how the particularities of context, and the make-up of the host communities, inform the process of social capital formation. Stevenson's (2016) conclusions about the uneven acquisition of social capital in a study of two London festivals is one of the few exceptions. In addition, few studies try to address the extent to which gains made in building social capital sustain over time. Legacy has attracted increasing attention from event researchers in recent years, especially in the large sports event arena (Preuss 2019). Theoretically, it is thought that events can generate lasting legacies of all kinds, but understanding how sustained outcomes can be achieved effectively and for whom remains limited. Legacy always features very strongly in bid documentation and in event advocacy discourse, as in the case under study. However, it is proving difficult to translate legacy aspirations into tangible realities (Chen and Misener 2019). Smith (2012: 127) has even argued that event legacy is 'best understood as a discursive device that is used to justify event projects'. In this context, this study concerns itself with the question of social capital in the post event context, asking whether the relationships and networks cultivated endure once the event has ended.

\section{Methodology}

This study adopts an interpretivist epistemology (Bryman, 2012). Yin (1994) subdivides case studies into single or multiple studies and in this research the authors opted for a single case study for two reasons. Firstly, this was the inaugural UK City of Culture which meant no direct comparison could be made. Second, the host city presents a study context characterised by particular social, cultural and spatial divisions. The primary data were gathered in 2017 and this too was a strategic decision. The organisers of $\mathrm{CoC} 13$ were intent on promoting social inclusion, community relations and reconciliation both during the $\mathrm{CoC} 13$ year and into the future. Gathering the data when four years had passed gave an opportunity to investigate 
whether changes wrought during the year-long event continued to be felt, by whom and in what ways.

The authors adopted a qualitative approach in the form of in-depth interviews and focus groups. This mixed methods approach allowed the authors to triangulate the findings which added to the richness of the data (Hay, 2011). Given the uniquely contentious environment (Boland, Murtagh and Shirlow, 2018) the authors had to ensure that the sample was not biased towards one community (PUL or CRN) and the views of all respondents were treated with respect and sensitivity (Jordan and Gibson, 2004). Critical case sampling, a form of purposive sampling, was used to select the interviewees. As Saunders $(2016$, p.174) notes, 'purposive or judgmental sampling enables the researchers to use their 'judgement' to select cases that will best enable them to answer their research question(s) and to meet their objectives'. This form of sampling is appropriate when working with very small samples such as in case study research, and when selecting cases that are 'particularly informative' (Veal, 2006). All interviews were recorded, and each interviewee agreed to have the name of their organisation and their position published in this paper. In total, thirty one in-depth interviews were conducted and the sample included representatives from the City Council, Culture Company, the four Neighbour Partnerships, event organisers, community group leaders, venue providers and educationalists (see Table 1). To elicit as much information as possible, the authors combined the general interview guide approach with an open-ended approach (Brunt, Horner and Semley, 2017).

In conjunction with local community officers, the authors also organised 9 focus groups with 76 members of the local community who differed by age, sex, occupation and religion. Eight of these were organised through the Neighbour Partnerships, two per neighbourhood. Given the segregated nature of housing in the city the authors worked with local community officers to recruit an equal number of representatives from both the CRN and PUL communities on to each focus group. For logistical reasons this proved difficult in the Waterside Neighbourhood, so the author held a focus group in Irish Street (PUL) and another with residents from the Top of the Hill (CRN), both of which were attended by members of one community only. To capture the voice of the younger generation the final focus group was organised through REACH Across, a cross community youth organisation. 
All the data were analysed using thematic analysis which is a process of encoding qualitative information leading to what Mason (2002) refers to as 'data transformation', in which the information is condensed, clustered, sorted and linked. In terms of reporting the findings, emphasis was placed on providing 'thick descriptions' (Geertz, 1973, p.34) with quotations from both interviewees and the focus groups used to support the arguments presented. The qualitative fieldwork was supplemented by secondary research. Key documents reviewed included One Plan (Ilex, 2010), the official bid document Cracking the Code. City of Culture 2013, Derry City Council, 2010) and the Post Project Evaluation of City of Culture 2013 (Derry City and Strabane District Council, 2018), all of which proved to be important sources of information.

Table 1: Interview Participants (to be inserted here)

\section{Findings and Discussions}

This section begins by presenting some context on the study city. It then discusses the findings under the themes of bonding social capital, bridging social capital and legacy.

\section{Context}

Derry/Londonderry is the second largest city in Northern Ireland, the six counties that were partitioned from the rest of the island of Ireland in 1921 and became part of the UK. This partitioning ultimately led to the "Troubles" in Northern Ireland between 1968-1998 as the Protestant, Unionist and Loyalist (PUL) community wanted to remain part of the UK whilst Catholic, Republican and Nationalist Community (CRN) wanted independence. During the "Troubles" over 3,600 people were killed and Derry/Londonderry was one of the epicentres of violence. In total there were 244 fatal incidents in the Derry/Londonderry council area which equates to a death rate of 1.74 per 1000 of the population (Cost of the Troubles Survey, 1995 cited in Derry City Council 2014, p.45). The peace agreement signed in 1998 (the Good Friday Agreement) set out aspirations for a shared society but a legacy of fear, distrust and suspicion remained and twenty years on, Derry/Londonderry is still very much a divided city. The "Troubles" witnessed a significant population shift within the city with the majority of the Protestants leaving the Cityside and moving across the River Foyle to the Waterside. In consequence, a majority of the city's population now live in segregated areas i.e. CRN and 
PUL. This was summed up by Doak $(2018$, p.10) when he discussed the cage-like 'peace line' that physically separates the sole PUL housing estate in the city's West Bank from the surrounding CRN neighbourhoods. Housing segregation is mirrored in educational, social, leisure and cultural activities.

Cultural expression has often been the cause of conflict within the city, a notable example being the annual Apprentice Boys Parade. 'Culture wars' (Wilson, 2016) continue to be fought out in physical spaces through wall murals, flags, banners, curb painting, effigy burnings at bonfires and parades. Expressing culture in this way has helped to differentiate the PUL and CRN communities and maintain boundaries between them. In summary, "Derry/Londonderry is a unique city dealing with the fallout from thirty years of violent conflict, contested cultural identities, social and spatial division, and severe socio-economic problems" (Boland, Murtagh and Shirlow, 2016, p.2).

According to Doak (2014, p.288) the decision to bid for the UK CoC13 designation can be viewed as "an entrepreneurial turn" in the city's governance. The bid document was strongly wedded to the One Plan (llex, 2010) which set out very ambitious regeneration targets for the city. This meant urban and economic regeneration were priority aspirations yet, Boland, Murtagh and Shirlow $(2016,2018)$ question the economic impact of CoC13. They note how a deepening economic recession negatively affected the flow of public and private capital into the city thereby undermining serious progress on the anticipated economic outputs. They also attribute the inflated economic targets set out in the bid document to neoliberal urbanism and discuss how not delivering on these created frustration and disillusionment amongst those at the margins of society. On a more upbeat note, McDermott, Nic Criath and Strani (2015) discuss the positive socio-cultural impacts of CoC13. They focus directly on the cultural programming and discuss how the emphasis that was placed on public places, collective memory and traditional music served to convey some sense of hybrid identities. Citing examples such as Fleadh Cheoil and the Walled City Tattoo provide an interesting insight into how intercultural dialogue was achieved through the 'deconstruction of musical boundaries'. Building on this, Boland et al. $(2016,2018)$ discuss how there was clear evidence of transformative change in cross community relations. Boland, Mullan and Murtagh's (2018) paper, which focused on the impact on young people, adds weight to this argument. They 
refer to how CoC13 events and the use of sites such as Ebrington Square as a shared space brought about intercultural dialogue and cultural exchange. Based on their studies of $\mathrm{CoC} 13$, Boland et al. $(2016,2018)$ go as far as describing culture as a 'peace resource' which can bring about dialogue and tolerance to a segregated society'. This is in line with Nolan's (2014, p.122) assessment of the Year when he stated that 'the $\mathrm{CoC} 13$ delivered more than could have been thought possible in terms of community relations'. However, according to Doak (2018), the evidence of conflict transformation is far from conclusive. Citing examples of ethno-cultural contestation before and during $\operatorname{CoC} 2013$, he argues that the long-term contribution of the CoC13 to peacebuilding is uncertain. Doak $(2018$, p.11) is also critical of the decision to host the vast majority of the major events along a narrow corridor of regenerated riverfront, ' $a$ space that obfuscates rather than transforms conflict'. The authors of this paper hope to add to this debate by using the theoretical lens of social capital to examine how the CoC13 influenced community relationships in Derry/Londonderry in the immediate and longer-term.

\section{Bonding Social Capital}

Positively influencing community relationships and encouraging a city-wide sense of ownership of the event was an important challenge for the Culture Company, the independent company set up to plan and deliver the events programme for CoC13. Key to its strategy to encourage inclusivity was partnering with the four Neighborhood Renewal Partnerships already in existence in the city, and supporting the "Community Engagement Project" with $£ 876.689$ of public monies. Its mission was:

To support local residents and communities to engage and participate, to enable them to plan, generate their own events and programmes, and to maximise the potential of local assets for social cohesion, community development and economic benefit (Department of Social Development, 2015).

This project had multiple strands and involved appointing a Community Participation and Engagement officer to each neighbourhood. An official review found that through the project, 55,083 adults gained access to new cultural opportunities and 10,200 schoolchildren were involved in CoC13 events/projects (Department of Social Development, 2015). The 
analysis of focus group data suggests that the kind of community engagement stimulated was very much associated with bonding capital. Focus group participants thought that events organised in the neighbourhoods created a heightened sense of connectedness and community spirit and this was captured in the following quote:

Some of the events that were organised in our neighbourhood were basic yet you felt you were part of something special... it was a chance to enjoy yourself with friends and family (Shantallow Focus Group).

One of the core guiding principles of the City of Culture bid was to "bring those on the edge of the city's cultural life to the heart of it" (Derry City Council, 2010). To this end, the community engagement officers worked closely with the city's most disadvantaged groups. The Community Engagement and Participation Officer for the Triax Neighbourhood, for example, discussed how she sourced tickets for events and arranged transport for the elderly and those with disabilities. In one case, she went as far as providing clothing, tickets and transport for a group of homeless alcoholics so they could attend a concert by the legendary rock band "Status Quo".

A core target group for $\mathrm{CoC} 13$ was families. Indeed, the majority of the events organised within the neighbourhoods were family orientated, creating opportunities for families to bond and enjoy themselves together. At city level, Boland et al. (2016) discuss how the development and promotion of Ebrington Square (a former British Army barracks) as a neutral venue was significant in terms of shared space. Once a 'no go area' for Catholics it became a 'depoliticised space' and the site for numerous COC13 events. A participant from the "Hillcrest mother and toddler focus group" made reference to Ebrington saying how she and her friends felt $\mathrm{CoC} 13$ changed the way families now view and engage with events at both neighbourhood and city level:

It seems that families got used to going out as family during $2013 \ldots$ now if there is anything on you see all these families out walking around enjoying the atmosphere, which is nice and good for the city in general. Much credit must be given to the event organisers for making these events family friendly and safe. I 
wish this neighbourhood and the city in general was like this when I was growing up.

A number of focus group participants spoke of the strong sense of pride they felt for their neighbourhood during 2013. One participant in the Triax focus group discussed how her area was often in the news for drugs offences and sectarian attacks, so she was delighted that the events organised by her community during $\mathrm{CoC} 13$ created headlines for the "right reasons"... "it showed what our community really can do if we pull together". According to the Manager of the Outer West Neighborhood Partnership, the realisation that "we are stronger if we work together" was one of the legacies of CoC13:

The experience gained during CoC13 has made the neighborhoods want to help themselves rather than waiting to see what the local council can do for them. In our area for example, since 2013 we have run a big Christmas festival which is run by the community for the community, generating joy and much needed income (No. 3).

The Shantallow Neighborhood Partnership Manager agreed: she discussed how CoC13 inspired a local history society and gave them the confidence to submit plans to develop a heritage trial. These examples point to the effects of the Year lasting beyond the event itself and link directly into Coleman's (1988) argument that strong healthy networks are essential for growth and prosperity, in effect for building sustainable communities.

It is important to note, however, that whilst $\mathrm{CoC} 13$ helped to build bonding social capital, some of these neighborhoods already exhibited high levels of social capital. The fear and distrust between the CRN and PUL communities perpetuated during the "Troubles" led to heightened in-group social cohesion (Murphy, 2008, Leonard, 2004), and these strong community networks still exist in PUL and CRN dominated neighborhoods. Many of the smaller events took place in housing estates dominated by one community. For instance, in the Shantallow area where 43 funded projects/events took place, $87 \%$ of the 4827 participants came from the CRN community compared to only $7 \%$ from the PUL community" (Shantallow Area Partnership, 2014). Overall, a key finding of this study is that CoC13 hooked into these networks, strengthening intra-community bonds even further: 
The Troubles had a major impact on this community...we relied so much on each other to get through the heartache and hardship. The people here went through a lot and I suppose it explains why the community is still so "tight" ... people still rely on each other and share their problems. I think CoC13 strengthened this bond, but in a good way as it brought us together on a joyous occasion... unlike the Troubles. (No. 22).

Segregation remains a ubiquitous feature of life in Derry/Londonderry (Wilson, 2016), a city where cultural symbols like flags and murals continue to be used by both CRN and PUL to mark their territories (NicCraith, 2013). It is therefore not surprising that the opportunities to create cultural performances presented by CoC2013 succumbed to the deeply entrenched divisions felt by city residents:

I wouldn't want to be seen at an event over there (City side) with all the tricolors (Irish National Flag) and all. I do not think we (PUL community) would be welcome anyway (Irish Street Focus Group).

Thus, even though the Culture Company went to great lengths to make the neighborhood events inclusive and open to all, the evidence suggests that exclusivity was sometimes fostered instead. This finding supports McGrellis" (2004) argument that bonding social capital can serve to perpetuate rather than break down entrenched divisions in a city like DerryLondonderry.

\section{Bridging Social Capital}

The official bid document discussed how CoC13 would help bring the CRN and PUL communities closer together. A publicly appointed committee with representatives from both communities oversaw the work of the Culture Company and the latter tried to work around local sensitivities to design a programme that would encourage inclusivity and cross-culture understanding. While the funding criteria did not specifically state that an event must improve cross community relations, it was made clear that the spirit of $\mathrm{CoC} 13$ was for people to "celebrate and share" their culture (No. 2). To this end, projects that were seen to be overtly sectarian or promoting a political cause were rejected. 
As might be expected, encouraging cross-community interaction was not an easy task. While the numerous spectator type events attracted cross-community audiences, the findings suggest that social interaction tended to be fleeting and superficial, as indicated in quotes from focus group participants:

At the Sons and Daughters (a concert which had artists from both communities) I talked to the person next to me, they even offered us one of their sweets but this was out of politeness nothing more. I was not going to ask if they were from the CRN or PUL community and I did not care. I was there with my family to listen to the music, not to make friends (Irish Street Focus Group).

I went to the St Patrick's Day celebration that was organised through the churches. They (PUL) sat on one side we (CRN) sat on the other. It was a lovely event but despite some small "small talk" after the event, the crowd did not mix (Triax Focus Group).

These passive encounters did not build new ties between disparate groups, although this is not unexpected. These findings mirror those of existing studies on other kinds of events (e.g. Wilks 2011). In contrast, a number of other events specifically designed to stimulate a high level of cross community interaction and integrated into routine service offerings in the city seemed more effective. Most notably, CoC13 organised a range of cross community events through the city's schools with the aim of encouraging students to work together, develop connections and build trust. The vast majority of young people in Derry-Londonderry are educated in segregated schools. According to Ben-Nun (2013) a segregated school system has kept CRN and PUL students from meeting and interacting naturally with one another, thus intensifying existing fears and stereotypes. The following quotes from a teacher and student of a local high school illustrate how CoC13 helped build bridging social capital:

Our school (St Brigid's - CRN) was involved in a cultural project /event with the All Saints School in the Waterside (PUL).... For a lot of our children living in Shantallow 
(CRN) up to this point they had no contact with the other community (PUL). The feedback from the children was very positive.... The children realised they were all the same. Once you work together and integrate children in something like a cultural event you create a bond that goes beyond all the political nonsense and I know from talking to the students some of them are still in contact (No. 17).

I am really into music so this it was a great project for me personally... I did enjoy working with students from the other school they were lovely, so friendly. I was amazed how well we got on and how much we had in common. I wish we could do more projects like that (No. 31).

Nevertheless, while this feedback is positive, the long-term effectiveness of projects coordinated through the schools in Northern Ireland more generally has been questioned by McGrellis (2004) who argued that more informal settings provide better opportunities for young people to develop bridging social capital. Some CoC13 events provided a less structured environment where social contact could happen more informally. Radio One's Big Weekend, for instance, attracted young people from both the PUL and CRN communities. According to PUL participants from the Youth Forum Focus Group, these larger events provided opportunities for young people to transcend the physical boundaries imposed on their generation by the "Troubles":

When you went to an event like the big weekend you didn't ask or care what religion the people you met were from - everyone was just having fun and proud that these big acts were performing in our city... CoC13 was like a big party and since then my friends and I feel much more comfortable going over to the Cityside (CRN) for a night out (Female participant, Youth Forum Focus Group).

It sounds weird but I think CoC13 made the city smaller... What I mean is that I attended events in parts of the city I would not have dared go out in before and you felt safe (Male participant, Youth Forum Focus Group). 
At the other end of the age spectrum, there were examples of bridging social capital being built, or in some cases rebuilt, through City of Culture events. During the "Troubles", fear and in some instances intimidation resulted in a significant population shift within the city with the majority of the Protestants (PUL) leaving the Cityside and moving across the River Foyle to the Waterside (Shirlow et al. 2005). A Community Officer in the Outer West Neighbourhood discussed one event that specifically intended to get "forgotten friends of the Troubles" to come together and reunite:

\begin{abstract}
Here in Rosemount we organised a "Thanksgiving day" celebration. Rosemount was one of the most "mixed" areas in the city until the Troubles and then there was an exodus of Protestants (PUL) to the Waterside. This "thanksgiving" celebration was basically a forty year reunion with a three-course meal and concert. For some Protestants (PUL) this was the first time they felt "able" to come back to Rosemount, a neighbourhood they grew up in. We asked each person to bring old photographs and from these we created an exhibition that brought back a lot of good memories (No. 20).
\end{abstract}

Whilst this particular event was well attended by older people from both sides of the community (PUL \& CRN), in general, the study found that this cohort was less likely to attend or participate in cross community events. Unsurprisingly, their experience and first-hand knowledge of the "Troubles" had played a part in fashioning their contemporary attitudes. This came through strongly during the focus group with Irish Street residents (PUL) - the majority of which had moved to the Waterside during the "Troubles":

I would not attend an event organised by them (CRN). It is hard to forget $-I$ just do not trust them (Irish Street Focus Group).

I could count on one hand how many times I have went over to the city-side. I do not trust the crowd over there (CRN) during the day, never mind when they are dressed up in fancy dress costumes (referring specifically to the Halloween Festival) (Irish Street Focus Group). 
Age was also a factor within the CRN community. Many of the older CRN respondents who lived through the "Troubles" and had direct personal experience of violence and hurt questioned the value of cross community events; it seemed division had become an accepted part of their lives. These quotes were in stark contrast to the views expressed by middle-aged males and females from the same neighbourhood who seemed to be less entrenched in the past:

It wasn't about whether you were a Catholic (CRN) or Protestant (PUL), it was about the city and everybody coming together (Irish Street Focus Group).

I think during $\mathrm{CoC} 13$ the people of the city were focused on the event rather than where it was located or who organised it, people were more carefree. Personally the past never really came into the equation for me, it was about living the moment (Irish Street Focus Group).

While there were exceptions, younger people were also much more open to forging cross community relationships through events:

It is weird for people my age because we didn't live through the "Troubles" yet we are living in the aftermath of it. You can see the divided in the city in places like the Diamond and Fountain Street where there are walls built around the two communities keeping them apart. It is hard to get your head around...I think that is why the young people in the city were so happy just to go to the big events during $\mathrm{CoC} 13$ and not have to worry about which side you were from (Male participant, Youth Forum Focus Group).

These data suggest that CoC13 clearly created "moments" when people in the city collectively enjoyed shared experiences and produced shared memories, probably in ways that would not have been possible in the midst of ordinary, routine city life. It is difficult to know quite how these memories will sustain, but the positivity of the responses, especially from younger respondents, gives ground for optimism. One of these "moments" was the Return of Colmcille Pageant. Specifically designed to be politically neutral and appeal to all generations, this two 
day festival encouraged the PUL and CRN communities to work together to produce a show that celebrated a fifth century saint who had traditionally been a contested figure within the city with both communities claiming ownership. It attracted over 40,000 people and was choreographed around the banks of the River Foyle which has historically served as a natural dividing line between PUL and CRN territories. Making the river the centre of the celebration unsettled the divisions between the two sides of the city and challenged the liminality of the river space (McDermott et al., 2015). The spatial transformation helped cultivate new social interactions between the 800 volunteers that planned and produced this spectacular event, as encapsulated in the following two quotes:

I volunteered for Return of Colmcille Pageant through the North West Volunteer Centre. It was an excellent experience working with people from across the city... it was a project where religion or political opinion didn't matter. We all got on so well and I am proud to say I was involved in such a spectacular event the people of the city enjoyed (Ulster University Student Focus Group).

I was a volunteer at the Return of Colmcille Pageant and I also helped out at a few other events like the Walled City Marathon and the City Triathlon. It was time consuming but well worth as I learnt new skills and made new friends... yes this included people from the Cityside who I would never come into contact in daily life (Greater North Focus Group).

In addition to the sense of celebration and community spirit created through participating in community events, strong bonds formed during the planning of these events. In the build up to $\mathrm{CoC} 13,638$ volunteers participated in event related workshops (Department of Social Development, 2015), and according to the Community Engagement Project Manager "partnership working was the cornerstone of the CoC13". She discussed how in her neighborhood alone, 39 community/voluntary organisations were involved in hosting events and many of these worked together to secure funding and organise a joint event. For instance, the "Don't Drink Dribble Easter Camp" saw Oxford United Football Club collaborate with a number of community groups in the Shantallow area. The event targeted 6-16 year old males with an aim of increasing physical fitness and raising awareness of the dangers of alcohol and drugs. Cooperation at this level created goodwill between key stakeholders. According to 
Falk and Kilpaptrick (2000), this type of shared participation and learning is an excellent way of building bonding social capital within neighborhoods. Another example of good planning was the Fleadh Cheoil (an annual festival of Irish culture) that was hosted in Derry/Londonderry as part of its $\mathrm{CoC} 13$ programme. The lead partner in delivering the festival was An Gaelaras, and one of its strategic objectives was to make the 2013 edition "inclusive of the entire community in the city". To this end, it forged a strong working relationship with the Londonderry Bands Forum, an organisation that represents PUL marching bands in the city, inviting its representatives to sit on subcommittees to develop the Fleadh Cheoil engagement programme. In partnership, it was agreed to stage Fleadh Cheoil 2013 events in both the Waterside and the Cityside, and to involve volunteers from both communities. Perhaps even more significantly, four PUL bands took part in the official programme, and performed in one of the main public spaces in the Cityside:

The fact that four loyalist bands played at the Fleadh Cheoil was crucial as it opened the door for members of the PUL community to come over to the cityside and enjoy the event (No. 7).

Programming decisions like this challenged and disrupted routine representations, perceptions and uses of spaces in the city, thereby helping to neutralise space and break down not only physical but also mental barriers to parts of the city strongly associated with particular community groups. Mirroring this in an organisational context, the Managers of An Gaelaras and the Londonderry Bands Forum discussed how the Fleadh Cheoil helped build trust and respect between what were once diametrically opposed organisations. Their relationship has grown since 2013 and this is testament to the groundwork done in the build up to the Fleadh Cheoil and the bridging social capital created through that process. They have continued to work together on joint projects such as the Pan Celtic Festival (2014) and Driochead (2015), thus continuing the circulation of social capital and creating one of the positive legacies of $\mathrm{CoC} 13$.

Legacy 
An overriding aim of $\mathrm{CoC} 13$ was to bring about positive social change, and the data presented here suggest that it was instrumental in building both bonding and bridging social capital. However, the findings also provide multiple insights into the difficulties involved in seeking to build bridging capital between diverse societal groups. Equally, they underscore the potential negativities associated with deepening bonding capital in contexts where societal divisions are already deeply entrenched. Furthermore, the evidence points to an ebbing away of some of the momentum generated during 2013 because of a lack of legacy planning and investment. This was not reflected in the official Post Project Evaluation (PPE) however, which described CoC13 as "remarkably successful" (Derry City and Strabane District Council, 2018, p.4).

The PPE discusses how as a result of CoC13, many of the culture organisations in the city have established new relationships and collaborative partnerships both locally and internationally. In addition to providing the impetus to complete capital projects such as the Guildhall, Ebrington Square and St Columb's Hall the PPE discusses how music programming has continued to flourish post 2013 citing examples such as the International Pan Celtic Festival (2014 \& 2015), Music City (2015 \& 2016) and the continued success of the Choral Festival. The PPE (Derry City and Strabane District Council, 2018) also cites figures from the Citizen Survey 2015 which found that $43 \%$ of residents of the most deprived areas rated arts and culture activities in the city as excellent or very good compared to $10 \%$ in 2009 . However, the report does warn that these figures should be treated with "extreme caution" because the 2015 Citizen survey was undertaken using a different methodology to the 2009 survey and with a smaller sample limiting the comparability of the results (Derry City and Strabane District Council, 2018, p17). It should also be noted that just over half of the event organisers involved in the CoC13 events completed an evaluation form (Derry City and Strabane District Council, 2018). These two methodological weaknesses plus Doak's $(2018, p 6)$ concerns over impartiality (the PPE was compiled by one of the organisations responsible for delivering CoC13) suggest that the information in the PPE must be "critically reviewed" and used with caution. To this end the authors of this study would question if the term "remarkably successful" cited in the PPE is an accurate description of the cultural legacy. Similar to what Boland et al. $(2016,2018)$ found in relation to the economic legacy, the feedback from the respondents in this study was that the culture legacy fell short of the "inflated" bid promises, 
creating a sense of disappointment and frustration. This is apparent in the following quotes from focus group participants who seemed to be suffering from what Smith (2012, p.151) termed an "anticlimactic hangover":

"During the year the city was on a high but I think the atmosphere deflated very quickly... we were promised that UK13 would be start of something new and I think the people of the city have been let down" (Female Respondent, Hillcrest Mother and Toddler Focus Group).

"I think you could describe it as a feast and a famine. There was a great buzz in the city and there was a strong sense of togetherness and pride especially at the larger events. Then it stopped. We still have the Halloween Carnival, the Martine Festival and the Jazz Festival but these were all up and running prior to 2013" (Male Respondent, Outer North Neighborhood Partnership).

The last respondent raises a valid point; with the exception of the Burning Man (2015), Derry/Londonderry has not hosted any new major events since 2013. Yet, in a survey conducted as part of the city's Good Relations Strategy (2014-17) the residents cited events as the best way to improve cross community relations. Foley et al. $(2012$, p.92) argued that "if the one-off opportunity for dialogue, sharing and expression of identity is not sustained, then the positive benefits gained through an event/s are likely to evaporate as quickly as they were formed". The following quote points to some evidence of this in Derry/Londonderry post CoC13:

"CoC13 certainly broke down barriers between the communities and it was great to see both communities coming together to enjoy big events like the Fleadh Cheoil and Lumiere. But this seems to have fizzled out... as far I can see we still live in a segregated city and $\mathrm{CoC} 13$ is nothing more than a nice memory" (Male participant, Youth Forum Focus Group).

Coinciding with a period of austerity and cuts to public spending, the post 2013 period did not see continued legacy investment forthcoming. Central and Local Government committed $£ 4$ million to a legacy fund but this ended in March 2015 and was described by a Senior 
Programmer as "a mere drop in the ocean" compared to what was needed to create the meaningful legacy promised in the official bid document:

"The tragedy is that this lack of investment in legacy has put in jeopardy all of the positive impacts of $\mathrm{CoC} 13$ in terms of community morale, the empowerment of ordinary people through culture and creativity and the real sense of inclusion that 2013 has fostered" (No. 2).

The managers of the Neighbourhood Partnerships voiced their frustration at this lack of investment in legacy and cited funding as the main reason why their neighbours were not able to build on the foundations laid in during 2013:

"A major part of the bid was legacy and the City Council has not delivered. In 2013, 43 events were organised by volunteers within this neighbourhood, only two have survived due to the lack of funding... so all the talk about inclusion and building intra and inter community relations through events seems to have been shortlived. I think funding has been the big issue" (No. 5).

"There is no doubt that 2013 was a success but in terms of legacy it simply has not happened. The Waterside Music Trial, for instance, which was organised by a cross community group of volunteers and was very well supported by both communities has not ran since 2015 due to funding issues. Very disheartening for those involved, and for me" (No. 6).

At city level, popular events such as CultureTECH and the Walled City Tattoo have been have either cancelled or downscaled because of the lack of funding. From a strategic perspective however, funding was not the only issue. A lack of legacy planning was also evident. The City Council was responsible for legacy and a number of Programmers and Managers expressed their disappointment with how it was handled:

"With hindsight one of the biggest mistakes and regrets was that not enough attention was paid to legacy...Throughout the planning stages there was 
uncertainty over funding to deliver the programme never mind what was going to happen post 2013" (No. 1).

During this interview the Manager for Arts and Culture went on to discuss how the short lead in time made legacy planning more difficult:

"We won the bid in July 2010 which meant we had 2.5 years to get ready. Our successor (Hull) won their bid in November 2013, which give them over 4 years to plan and think about legacy. I know they set up a separate department dedicated to legacy and appointed a Director of Legacy who visited Derry /Londonderry in 2016 to see what lessons they could learn from us" (No. 1).

The setting up of a legacy department within the City Council in 2015 following a restructuring process was described as an "afterthought" that lacked power and funding.

"The legacy of CoC13 didn't really get the attention it deserved because the Derry City Council was involved in restructuring under the RPA. This was a major distraction as the staff were not sure what was happening and there was uncertainty over their jobs. So in my opinion CoC13 didn't get the space it needed and deserved and the city has paid the price" (No. 4).

In this study, "the tent" was the most cited example of poor legacy planning. Rather than build a permanent indoor venue Derry City Council hired a 4,000-seater tent for the 12 months. Four years on, the consensus from study participants was that that this was a missed opportunity:

"It was a disgrace the money they wasted on the tent, and what is there now, nothing!" (Male Respondent, Triax Focus Group)

"It would have been nice if they had built a real indoor venue, one that would hold big gigs, like the Odyssey Arena in Belfast... There is nothing in this city for the young people; I suppose that is why there is so much under-age drinking and social disorder" (Female participant, Youth Forum Focus Group). 
The decision not to build a permanent venue was regressive because it would have provided another shared space, something that the city lacks at present (Derry City Council 2014). According to Song (2016), the use of public space to enhance interactions and create opportunities for the reciprocal respect of plural cultures is an important prerequisite for the reconciliation process.

\section{Conclusion}

Putnam (1993) suggested that the hallmarks of a successful society include the presence of trust, the expectation of reciprocity and the existence of networks. As communal celebrations which bring people together, events have the potential to cultivate human relationships that generate positive social outcomes for individuals and communities. The data offered many glimpses into how events can play a role in building sustainable communities by creating shared spaces and common foci of celebration, and offering opportunities to set historically embedded differences aside to find commonalities in more neutral interests like a favourite pop group or shared memories of a residential area. Crucially, the study found examples of how events can transform city spaces both physically and perceptually, disrupting strong place associations and, in line with Pløger, (2010) revealing new possibilities for how spaces might be reproduced in the future.

In line with existing studies, the data show that during $\mathrm{CoC} 13$, events helped to generate both bonding and bridging social capital. However, the nature of the social capital cultivated was strongly shaped, often negatively, by the long standing and ongoing political and sociocultural divisions that characterise the host city. While study participants reported a heightened sense of connectedness and community spirit at neighborhood level, the segregated nature of housing and the entrenched cultural and political divisions within the city meant that some events attracted only one community. Thus, in building intra community bonds they sometimes also fostered exclusivity. Nevertheless, a firm commitment on the organisers' part to encourage inclusivity, cross-cultural cooperation and understanding led to many positive outcomes in terms of increased familiarity and contact across different communities. In spite of many difficulties, bridging social capital was generated between those involved in the planning of $\mathrm{CoC} 13$ events. Working cooperatively together, organisers and volunteers built up trust and goodwill, even when some of those involved were 
diametrically opposed politically. Some of these networks have remained active. Among event participants, it was found that older respondents with deeply entrenched views tended to be much less reluctant to support cross community interactions than their younger counterparts who were more open-minded and welcoming of the social opportunities that CoC13 presented. This points to the heterogeneous nature of "community": the CRN and PUL study participants were not homogeneous groups. Overall, the findings highlight the complexities at issue for events seeking to encourage cross community social interaction and build social capital. Events are produced within the context of prevailing power relations (Waterman 1988) and there is a real need to take account of the historically and spatially embedded nature of human relationships. Stevenson (2016) recommends that more research is needed into the unevenness of social capital development in event settings and this study concurs. Since a limitation of this study is that it is confined to one city, future research should aim to be more comparative, paying particular attention to the heterogeneous nature of "community" and to the role that socio-cultural factors like age, ethnicity, gender, class and religion may play in influencing the formation of forms of capital.

The question as to whether the social connectivity engendered during $\mathrm{CoC} 13$ would endure in its aftermath was important in this study. The findings show that some of the cross community networks and relationships that developed during 2013 have been maintained: some families are now more comfortable attending large cross community events, and some young people are more at ease mixing with their counterparts elsewhere. Some organisations have continued to work together on projects e.g. An Gaelaras and the Londonderry Bands Forum. All of these bode well for a shared future. However, the lack of legacy planning and sustained investment in events has meant that some of the long-term social goals of CoC13 have not been met and so it can be argued that in terms of community relations, the city failed to capitalise fully on the valuable resource that the CoC13 constituted. In this respect, an important conclusion to be drawn from this case study is that events have a role to play in building both bonding and bridging social capital in post conflict/divided societies, but as in other contexts, if this is not sustained then the positive benefits gained soon fade away. In terms of future research, there is a real need to develop a better understanding of the social legacy of events, particularly in highly complex contexts like the one studied here. Much closer interrogation of the positive policy narratives that currently surround event legacies is 
recommended so as to identify the kinds of change that urban communities can expect to experience if their city's bid to host a large scale event succeeds.

\section{References}

Adkins, L. (2005) Social capital. The anatomy of a troubled concept. Feminist Theory, 6(2), 195211.

Arcodia, C., \& Whitford, M. (2007). Festival Attendance and the Development of Social Capital. Journal of Convention \& Event Tourism, 8(2), 1-18.

Ben-Nun, M. (2013). The 3Rs of integration: respect, recognition and reconciliation; concepts and practices of integrated schools in Israel and Northern Ireland. Journal of Peace Education, 10(1), 1-20.

Boland, P., Mullan, L. and Murtagh, B. (2018) Young people in a city of culture: "ultimate beneficiaries" or "economic migrants"? Journal of Youth Studies, 21(2), 178-202.

Boland, P., Murtagh, B., \& Shirlow, P. (2016). Fashioning a city of culture: "life and place changing" or "12 month party" ? International Journal of Cultural Policy, 25(2), 246-265.

Boland, P., Murtagh, B. and Shirlow, P. (2018) Neoliberal place competition and culturephilia: explored through the lens of Derry-Londonderry. Social and Cultural Geography, DOI: 10.1080/14649365.2018.1514649

Bourdieu, P. (1986). The Forms of Capital. In J. Richardson (ed) Handbook of Theory and Research for the Sociology of Education, pp. 241-58. New York: Greenwood Press

Bridger, J. C. and Lulott. A. E. (2001) Building the sustainable community: is social capital the answer? Sociological Enquiry, 71(4), 458-472.

Brunt, P., Horner, S. and Semley, N. (2017) Research Methods in Tourism, Hospitality and Events Management. London: Sage.

Bryman, M. (2012) Social Research Methods. Oxford: Oxford University Press.

Chen, S. and Misener. L (2019) Event leveraging in a nonhost region: challenges and opportunities. Journal of Sport management (pre-print) 1-14. 
Coleman, J. S. (1988). Social capital in the creation of human capital. American Journal of Sociology 94 Supplement, S95-120.

Coleman, J. S. (1990). Foundation of Social Theory. Cambridge, MA: Harvard University Press.

Cuthill, M. (2010). Strengthening the "Social" in Sustainable Development: Developing a Conceptual Framework for Social Sustainability in a Rapid Urban Growth Region in Australia, Sustainable Development 18(6), 362-373.

Dale, A. and Newman, L. (2010). Social capital: a necessary and sufficient condition for sustainable community development? Community Development Journal 45(1), 5-21.

De Jong, A. and Varley, P. (2018). Food tourism and events as tools for social sustainability? Journal of Place Management and Development 11(3), 277-295.

Department of Social Development (2015). A Review of the Community Engagement Project - March 2013-March 2015, accessed via www.dsdni.gov.uk 17 $7^{\text {th }}$ February 2017.

Derry City and Strabane District Council (2018) Post project evaluation of city of culture 2013. Derry: Derry City and Strabane Council.

Derry City Council (2014). Good Relations Strategy (2014-17). Derry: Derry City Council.

Derry City Council. (2010). Cracking the Code. City of Culture 2013. Derry: Derry City Council.

Doak, P. (2014). Beyond Derry or Londonderry: Towards a framework for understanding the emerging spatial contradictions of Derry-Londonderry-UK City of Culture 2013. City, 18(45), 488-496.

Doak, P. (2018) Cultural policy as conflict transformation? Problematising the peacebuilding potential of cultural policy in Derry-Londonderry - UK City of culture 2013. International Journal of Cultural Policy. doi:10.1080/10286632.2018.1445727

Duffy, M. and Mair, J. (2018) The role of festivals in strengthening social capital in rural communities. Event Management, 22(6), 875-889.

Falk and Kilpatrick (2000). What is Social Capital? A Study of Interaction in a Rural Community, Sociologia Ruralis, 40(1), 87-110

Finkel, R. (2010). "Dancing around the Ring of Fire": social capital, tourism resistance, and gender dichotomies at up Helly Aa in Lerwick, Shetland, Event Management, 14(4), 275-285. 
Foley, M., McGillivary, D., \& McPherson, G. (2012). Event policy - from theory to strategy. London: Routledge.

Geertz, C. (1973). The interpretation of cultures: Selected essays. New York, Basic Books.

Getz, D. (2009). Policy for sustainable and responsible festivals and events: institutionalization of a new paradigm, Journal of Policy Research in Tourism, Leisure and Events, 1(1), 61-78.

Getz, D., Andersson, T. and Larson, M. (2006). Festival Stakeholder Roles: Concepts and Case Studies, Event Management, 10(2-3), 103-122.

González-Reverté, F. and Miralbell-Izard (2011). The role of social and intangible factors in cultural event planning in Catalonia, International Journal of Event and Festival Management, 2(1), 37-53.

Hay, C. (2011) Interpreting interpretivism interpreting interpretations. The New Hermeneutics of Public Administration. Public Administration, 89(1), 167-182.

Ilex (2010) Regeneration Plan for Derry-Londonderry. One City, one Plan, one Voice. Derry: Derry City Council.

Johansson, M. and Kociatkiewicz, J. (2011) City festivals: creativity and control in staged urban experiences. European Urban and Regional Studies, 18(4), 392-405.

Jordan, F. Gibson, H. (2004). Lest your data do the talking: researching the solo travel experiences of British and American women. In Qualitative Research in Tourism - Ontologies, Epistemologies and Methodologies. Phillimore, J. Goodson, L. (Eds.). London: Routledge.

Kusakabe, E. (2012). Social capital networks for achieving sustainable Development. Local Environment, 17(10), 1043-1062.

Laing, J. and Mair, J. (2015). Music festivals and social inclusion - the festival organizers' perspective. Leisure Sciences, 37(3), 252-268.

Leonard, M. (2004). Bonding and bridging social capital: reflections from Belfast. Sociology, 38(5), 927-944.

Liu, Y. (2017). The impacts of cultural event on networking: Liverpool's cultural sector in the aftermath of 2008, Impact Assessment and Project Appraisal, 35(2), 118-127.

Mason, J. (2002) Qualitative Researching, 2 ${ }^{\text {nd }}$ Ed. London: Sage. 
McDermott, P., Nic Craith, M., and Strani K., (2015). Public space, collective memory and intercultural dialogue in a (UK) city of culture. Identities: Global Studies in Culture and Power, 23(5), 1-18.

McGrellis, S. (2004). Pushing the Boundaries in Northern Ireland: Young People, Violence and Sectarianism. London: London South Bank University.

Misener, L \& Mason, D. S. (2006). Creating community networks: Can sporting events offer meaningful sources of social capital? Managing Leisure, 11(1), 39-56.

Misener, L. (2013). Events and social capital, in R. Finkel, D. McGillivray, G. McPherson, and P. Robinson, (Eds) Research Themes for Events (pp.18-30). Wallingford, Oxon, UK: CABI.

Mohan, G. and Mohan, J. (2002). Placing social capital. Progress in Human Geography, 26(2), 191-210.

Muir, J. (2011). Bridging and Linking in a Divided Society: A Social capital Case Study from Northern Ireland. Urban Studies, 48(5), 959-976.

Murphy, H. (2008). The Troubles, geographies of mental health in Northern Ireland and reconceptualising social capital, Critical Public Health, 18(1), 51-64.

Mykletun, R. (2009). Celebration of extreme playfulness: Ekstremsportveko at Voss, Scandinavian Journal of Hospitality \& Tourism, 9(2/3), 146-176.

NicCraith, M. (2013). Living Heritage and Religious Traditions: Reinterpreting Columba/Colmcille in the UK City of Culture. Anthropological Journal of European Cultures, 22(1), 42-58.

Nolan, P. (2014) Northern Ireland peace monitoring report. Number 3. Belfast: Community Relations Council.

OECD (2017). Major events as catalysts for tourism, OECD Tourism Papers, 2017/02. Paris: OECD Publishing.

Ooi, N., Laing, J. \& Mair, J. (2015). Social capital as a heuristic device to explore sociocultural sustainability: a case study of mountain resort tourism in the community of Steamboat Springs, Colorado, USA, Journal of Sustainable Tourism, 23:3, 417-436.

Pickering, P. M. (2006). Generating social capital for bridging ethnic divisions in the Balkans: case studies of two Bosnian cities. Ethnic and Racial Studies 29(1), 79-103.

Pløger, J. (2010). Presence-experiences: the eventalisation of city space. Environment and Planning: Society and Space, 28, 848-866. 
Portes, A. and Landolt, P. (1996). The Downside of Social Capital, The American Prospect 26: $18-21$.

Preuss, H. (2019) Event legacy framework and measurement. International Journal of Sport Policy \& Politics, 11(1), 103-118.

Putnam, R. D. (2000). Bowling Alone: the Collapse and Revival of American Community. New York: Simon and Schuster/Touchstone.

Putnam, R.D. (1993). Making Democracy Work: Civic Traditions in Modern Italy. Princeton, NJ: Princeton University Press.

Putnam, R.D. (1995). Bowling alone: America's declining social capital. Journal of Democracy, 6(1), 65-78.

Quinn, B. (2013). Key Concepts in Event Management. London: Sage.

Quinn, B. \& Wilks, L. (2013). Festival connections: people, place and social capital, in, Richards, G., de Brito, M. P. \& Wilks, L. (Eds) Exploring the Social Impacts of Events, pp. 15 - 30. Abingdon, Oxon: Routledge. (ISBN: 9780415 539616)

Quinn, B. and Wilks, L. (2017). Festival heterotopias: spatial and temporal transformations in two small-scale settlements. Journal of Rural Studies, 53, 35-44.

Rutten, R., Westland, H. and Boekema, F. (2010) The spatial dimension of social capital. European Planning Studies, 26(7), 781-71.

Saunders, M. (2016). Research Methods for Business Students, $7^{\text {th }}$ ed. Harlow: Pearson Education.

Schulenkorf, N., Thomson, A., \& Schlenker, K. (2011). Intercommunity sport events: Vehicles and catalysts for social capital in divided societies. Event Management, 15(2), 105-119.

Shantallow Area Partnership (2014). Outer North Arts and Culture Programme. Derry: Northside Village Centre, Derry.

Shirlow, P. and Murtagh, B. (2006). Belfast: Segregation, Violence and the City. London: Pluto.

Shirlow, P., Graham. A., McMullan, B., Murtagh, G., Robinson, \& Southern, N. (2005). Population Change and Social Inclusion Study Derry/Londonderry. Retrieved from http://cain.ulst.ac.uk/issues/population/popchangederry05.pdf. 12th January 2017.

Smith, A. (2012). Events and urban regeneration. The strategic use of events to revitalise cities. London: Routledge. 
Song, J. Y. (2016). DMZ Cultural Center: the role of shared space in the Korean Peninsula crisis, Dearq, 18, 56-67.

Stevenson, N. (2016). Local festivals, social capital and sustainable destination development: experiences in East London, Journal of Sustainable Tourism, 24(7), 990-1006.

Veal, A. (2006). Research methods for leisure and tourism - A practical guide ( $3^{\text {rd }}$ ed.). London: Prentice Hall.

Waterman, S. (1998). Carnivals for elites? The cultural politics of arts festivals. Progress in Human Geography, 22(1), 54-74.

Wilks, L. (2011). Bridging and bonding: social capital at music festivals. Journal of Policy Research in Tourism, Leisure and Events, 3(3), 281-297.

Wilks, L. and Quinn, B. (2016). Linking social capital, cultural capital and heterotopia at the folk festival, Journal of Comparative Research in Anthropology and Sociology, 7(1) ISSN 2068 - 0317, http://compaso.eu. doi: 10.21427/ D7BP6G

Wilson, R. (2016) Northern Ireland peace monitoring report. Number 4. Belfast: Community Relations Council.

Yin, R. (1994). Case study Research: Design and Methods. London, Sage.

Ziakas, V (2013). Fostering the social utility of events: an integrative framework for the strategic use of events in community development. Current Issues in Tourism 19(11), 11361157. 